\title{
Relating resource use to body condition and survival of Ozark hellbenders Cryptobranchus alleganiensis bishopi
}

\author{
Christopher R. Ayers ${ }^{1, *}$, Jerrold L. Belant ${ }^{1}$, Catherine M. Bodinof ${ }^{2}$, \\ Jeffrey T. Briggler ${ }^{3}$, Joshua J. Millspaugh ${ }^{2}$ \\ ${ }^{1}$ Carnivore Ecology Laboratory, Forest and Wildlife Research Center, Mississippi State University, Mississippi State, \\ Mississippi 39762, USA \\ ${ }^{2}$ Department of Fisheries and Wildlife Sciences, University of Missouri, Columbia, Missouri 65211, USA \\ ${ }^{3}$ Missouri Department of Conservation, Jefferson City, Missouri 65109, USA
}

\begin{abstract}
Endangered species conservation requires the understanding of factors affecting animal condition and performance. However, commonly investigated resource-use metrics such as habitat selection may not accurately predict biological outcomes because some components of habitats are more important to animals than others. We examined individual level resourceoutcome relationships and the relationship between 2 biological outcome metrics - body condition and fate-in Ozark hellbenders Cryptobranchus alleganiensis bishopi, which were recently included on the US Endangered Species List by the United States Fish and Wildlife Service. Our regression models included proportional use of a stream substrate, average distance to cover, distance moved, and water temperature as predictors of daily change in body condition or fate of captive-reared, radio-marked released hellbender populations in 2 sections of the North Fork of the White River in Missouri in 2008-2009. Distance moved between observations helped predict change in body condition, but no variable predicted fate well. We infer that resource use of selected substrate features did not predict biological outcomes in the short term. Our results indicate that energetic metrics such as distance moved can predict biological outcomes better than use of substrate features. Body condition did not correlate with fate and may be a poor indicator of an animal's ability to survive and reproduce. These investigations improve our understanding of influences on biological outcomes in hellbenders, which may improve efficacy of management and conservation of this species through efforts to increase abundance of important resources to improve hellbender condition and performance.
\end{abstract}

KEY WORDS: Hellbender - Cryptobranchus alleganiensis bishopi $\cdot$ Resource use $\cdot$ Biological outcome $\cdot$ Body condition $\cdot$ Survival $\cdot$ Habitat

Resale or republication not permitted without written consent of the publisher

\section{INTRODUCTION}

Persistence of a wildlife species depends on individuals' abilities to survive and reproduce (Darwin 1959). Threatened and endangered species are often faced with greater difficulties in gaining resources necessary for survival and reproduction than common species (Thomas 1990), yet it is not always known how resource use affects animals at population and indi- vidual levels. Investigations into how individual resource use affects individual biological outcomes should be conducted to gain reliable knowledge of ways of improving population sustainability (Aldridge $\&$ Boyce 2008). These investigations are generally lacking in the literature because of difficulty in collecting resource use and biological outcome data or because it is assumed that selection for resources leads to beneficial outcomes (Thomas \& Taylor 2006). 
Conservation of threatened and endangered species requires knowledge of factors that affect animal survival and reproduction to improve management and for protection of beneficial resources (Halstead et al. 2011, Nie et al. 2011). Management and conservation of resources necessary for population sustainability requires knowledge of how resources affect the species of concern. Resource management often focuses on habitat or landcover types, but may require finer scale investigations of relationships between habitat components and their effects on animals (Gaillard et al. 2010). For example, Blouin-Demers \& Weatherhead (2001) observed extensive predation of bird nests by black rat snakes Elaphe obsoleta obsoleta in forest edge habitat; however, thermoregulation was found to be the ultimate driver behind selection for the habitat type, and exploitation of nests was secondary or coincidental. Ayers et al. (2013) hypothesized a gradient of the direct effect of resource use metrics on biological outcomes (i.e. measures of animal condition or performance) of animals. They described using metrics closely tied to energetics because of the effects of energy use on body condition, survival, and reproduction in many species. Movement metrics have been successfully used as predictors of body condition, likely because of their close associations with energy use (Mautz \& Fair 1980, Ayers et al. 2013).

Using metrics of resource use that more directly affect animal biological outcomes will allow more accurate understanding of animal ecology and more effective efforts in conservation through management of specific resources. Biological outcome metrics can be used as indices of fitness (i.e. the ability to survive and reproduce; Gaillard et al. 2010, Homyack 2010). Categories of biological outcomes include physiological stress, body condition, survival, and reproduction. Examples of metrics in each category include fecal gluco-corticoid metabolite levels, percentage body fat, age, and lifetime reproductive success, respectively, which have an increasingly stronger association with fitness (Gaillard et al. 2010, Homyack 2010). We expect these outcome metrics to be correlated and, in some cases, expect metric with weaker associations with fitness to be causative of metrics with stronger associations with fitness. For example, chronic stress has been demonstrated to have a negative effect on reproductive success (Millspaugh \& Washburn 2004). By investigating and interpreting individual resource-outcome relationships, beneficial resource use (i.e. that which improves biological outcomes) can be identified using individuals with better levels (i.e. more beneficial to survival and reproduction) of the measured biological outcome.
Ozark hellbenders Cryptobranchus alleganiensis bishopi, 1 of 2 subspecies of giant salamander in North America, are a long-lived species listed as endangered by the United States Fish and Wildlife Service in 2011 (Gould 2011). Ozark hellbenders are isolated to freshwater streams in the Ozark region of Missouri and Arkansas (Gould 2011). The density of Ozark hellbenders has decreased consistently in recent decades (Wheeler et al. 2003). An increase in average hellbender age has also been assumed based on increases in average length (Peterson et al. 1983, Wheeler et al. 2003), indicating decreased survival of younger age classes.

Ozark hellbenders are most often found in cool mountain streams populated with crayfish Orconectes spp., which are their most common food source (Nickerson \& Mays 1973). Ozark hellbender resource selection and population dynamics have been examined (Peterson et al. 1988, Bodinof et al. 2012a,b), but the effects of resource use on individual biological outcomes have not been measured. Bodinof et al. (2012a) found similar hellbender selection for coarse stream substrate and shorter distances to rocks $\geq 15 \mathrm{~cm}$ in size for 2 populations of released hellbenders in the North Fork of the White River. Bodinof et al. (2012b) found different body conditions and survival probabilities between the same populations, but did not relate resources to these biological outcome metrics. Human use of and changes to hellbender streams have included removal of coarse substrate for making gravel and installing impoundments for reservoirs (Gould 2011). These changes can quickly reduce beneficial substrate and affect water temperatures. Effective management and conservation of beneficial hellbender resources depends on accurate measures of resource-outcome relationships.

We would expect biological outcome metrics to be closely correlated because sub-organismal physiological processes are recognized as having an effect on organismal survival and reproduction (Homyack 2010). For example, we would expect a similar positive relationship between a metric of body condition and a metric of survival in a population because survival often correlates positively with body condition (Hayes \& Shonkwiler 2001, Stevenson \& Woods 2006). However, correlations may not be consistent between indices with relatively weak associations with fitness (e.g. change in body mass) and metrics requiring more time to occur (e.g. aging). Body mass can fluctuate or provide inaccurate measures of energy storage expected to be important for survival and reproduction (Hayes \& Shonkwiler 2001). In the late 1970s, when populations were much denser, Peterson et al. 
(1983) collected length and mass data on hellbenders in the study area we used in the present study. They used these data to develop a log-transformed length to mass regression. Bodinof et al. (2012b) used this regression model (Model I) as a baseline for body condition of Ozark hellbenders in the same study area as that used by Peterson et al. (1983) and in the present study.

Our goal was to investigate relationships between resource use and biological outcomes (i.e. body condition and survival) in Ozark hellbenders. Our first objective was to test the use of 2 habitat components previously determined to be selected by Ozark hellbenders and 2 metrics related to energetics of Ozark hellbenders as predictors of variation in biological outcomes among individuals. Our second objective was to compare predictors of 2 biological outcomes (i.e. change in body condition and fate). We hypothesized that energetic metrics would predict biological outcomes better than use of substrate features selected by hellbenders, with greater movements and highest and lowest temperatures negatively affecting both outcome metrics. We also hypothesized that body condition would positively correlate with fate because the 2 outcome metrics are associated.

\section{MATERIALS AND METHODS}

\section{Study area}

The data used in the present study were collected by Bodinof et al. (2012a,b) from 2 populations of captive-reared free-ranging Ozark hellbenders in the North Fork of the White River, Missouri, USA, from May 2008 to August 2009. The watershed for this stream includes $3597 \mathrm{~km}^{2}$ of the Ozark region in southern Missouri. Landscape use primarily consists of woodlands $(61.9 \%)$ and crop and grassland (37.5\%). Stream flow averaged $21.4 \mathrm{~m}^{3} \mathrm{~s}^{-1}$. Substrate in the stretches of river for both populations was characterized by at least one relatively large patch of boulder interspersed with bedrock and finer substrates that was bordered up- and downstream by extensive gravel-pebble beds. Crayfish abundance was similar for both hellbender populations (Bodinof et al. 2012a).

\section{Data collection and analysis}

Veterinary staff at the Saint Louis Zoo implanted 36 captive-reared Ozark hellbenders with AVID passive integrated transponders and Sirtrack radio transmit- ters ( $\leq 5 \%$ of animal body mass; Bodinof et al. 2012b). All hellbenders received $10 \mathrm{mg} \mathrm{kg}^{-1}$ of enrofloxacin (antibiotic) following surgery and were monitored in captivity for 14 to $28 \mathrm{~d}$ and then reexamined. If sutures were dehiscing they were then repaired and monitored for an additional 14 to $28 \mathrm{~d}$; otherwise, animals were prepared for release. Any transmitter replacement surgeries were conducted by veterinary staff at the Saint Louis Zoo under the same sterile conditions as original implantations. All use of Ozark hellbenders and procedures on the animals were conducted in accordance with institutional, state, and federal guidelines for research and sampling of animals and endangered species.

Eighteen hellbenders were released at each of 2 sites separated by $17 \mathrm{~km}$ of river. We used 21 of these individuals (10 from the upper and 11 from the lower site) for all analyses; the remaining 15 were excluded due to mortality before $30 \mathrm{~d}$ or unknown fate. Hellbenders were monitored for $\leq 457 \mathrm{~d}$. Individuals were relocated using a VHF receiver about every $32 \mathrm{~h}$ except in winter, when locations were attempted weekly. We used VHF locations to determine proportional use of coarse substrate and mean distance to rocks $\geq 15 \mathrm{~cm}$ in size because these 2 resources were determined to be selected for in both populations (Bodinof et al. 2012a). Bodinof et al. (2012b) tested each hellbender for presence of the pathogenic amphibian chytrid fungus Batrachochytrium dendrobatidis before release and during any recaptures. Bodinof et al. (2011) investigated infection of the amphibian chytrid fungus as a cause of hellbender decline, but we did not use this as a predictor variable because only 4 individuals used in modeling tested positive and only one of these died. Additionally, 1 infected individual improved body condition, 1 declined, and 2 had little change. We concluded that infection did not warrant inclusion as a predictor at the detriment of model parsimony because a positive relationship between infection and survival and an inconsistent relationship between infection and change in condition does not make biological sense.

Each hellbender was recaptured and weighed at least once and we used the last of these capture events as our final observation to determine the difference between observed mass and expected mass following Peterson et al. (1983). Assuming the hellbenders used by Peterson et al. (1983) were healthy, we would expect healthy individuals in our study populations to achieve or exceed mass associated with total length from Peterson et al. (1983). Further, we would expect individuals conducting beneficial resource use to improve or maintain their relative body 
condition over time. For each hellbender, we calculated a body condition score as the difference between observed and expected log-transformed body mass $(\mathrm{g})$ based on total length $(\mathrm{mm})$ at release and final capture, separately. We used change in scores for each individual divided by number of days between these events as a dependent variable representing change in body condition in a set of generalized linear mixed-effects regression models (GLMM). Log 10 values of expected and observed body mass are shown in Fig. 1. However, for the 'Results' and 'Discussion' of
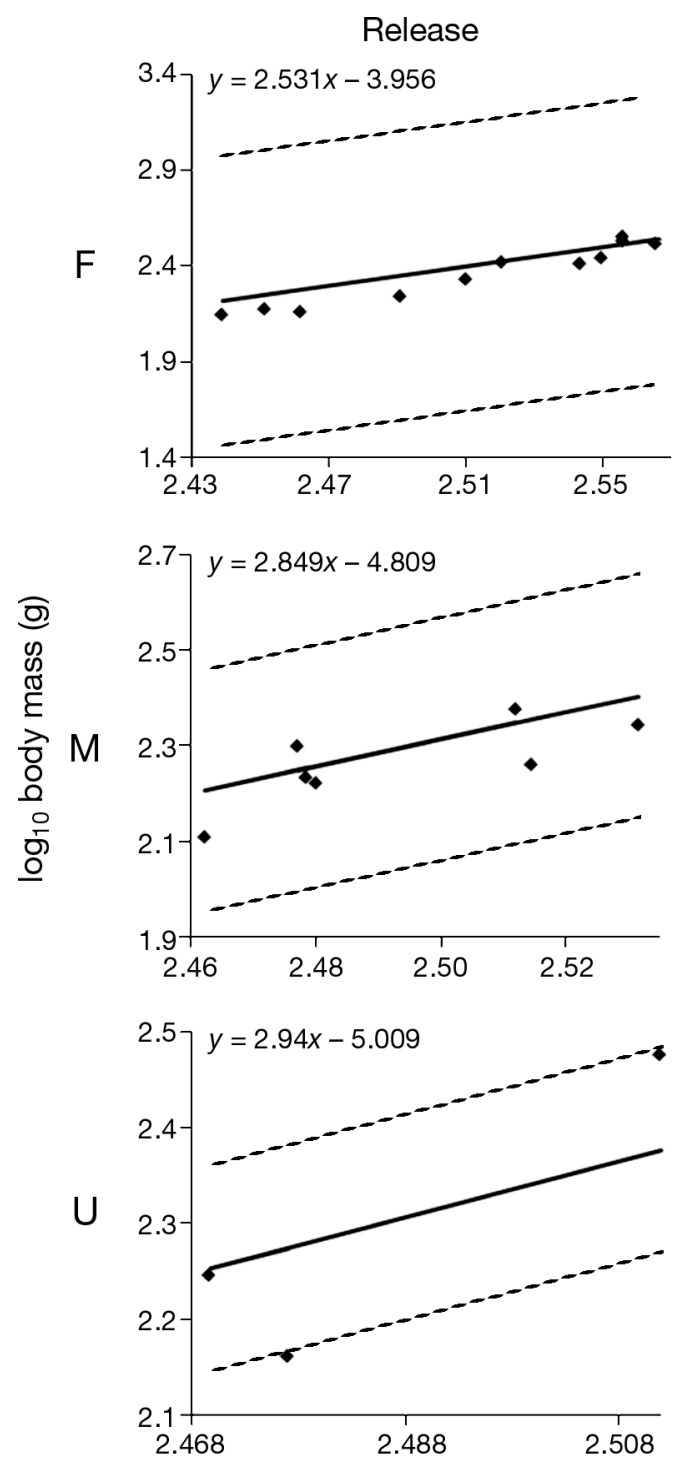

the present study we converted our body condition metric to the proportional difference between observed and expected body mass. We also used fate of each individual at the end of the observation period (i.e. August 2009) as an index of survival and a dependent variable in a second set of GLMMs. Table 1 shows a timeline of events for each hellbender.

We used proportion of locations characterized by coarse substrate (Coarse), mean distance to cover (Coarse), mean distance moved between relocations (Movement) (from Bodinof et al. 2012a), and the
Final
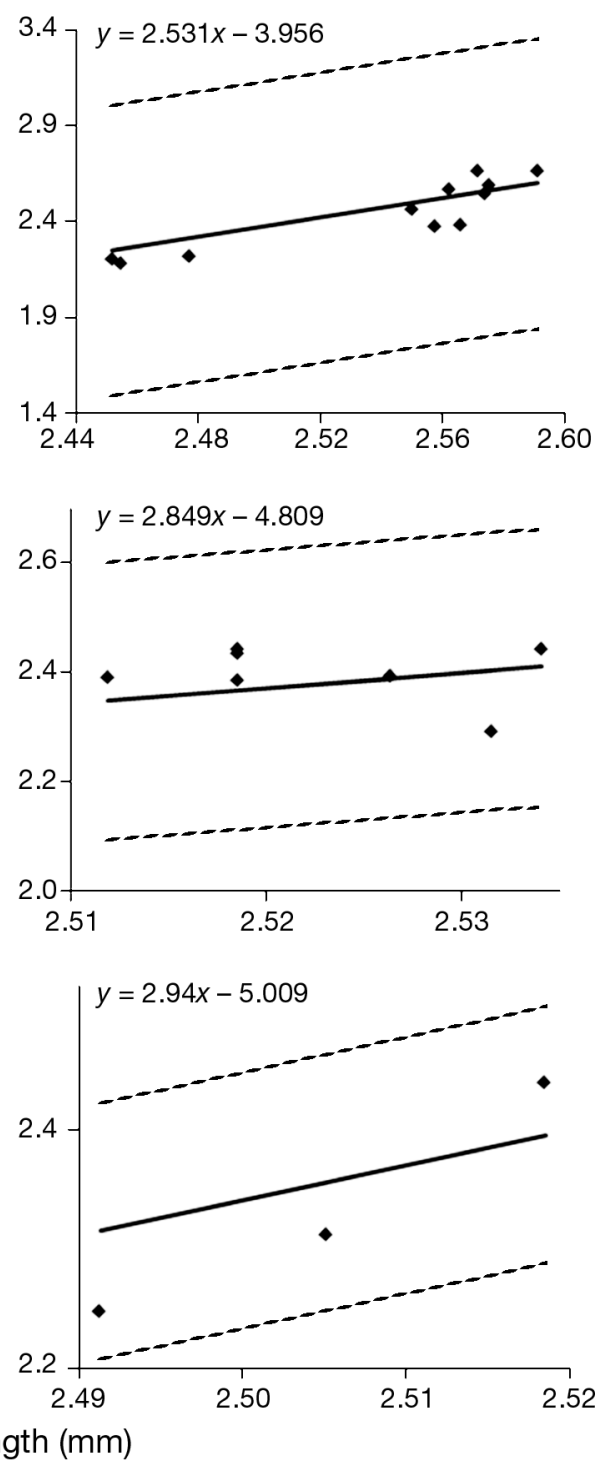

Fig. 1. Regressions between expected $\log _{10}$ body mass for observed $\log _{10}$ body length for Ozark hellbenders Cryptobranchus alleganiensis bishopi using sex-specific (F: female; M: male; U: unknown) Model I from Peterson et al. (1983). ( $)$ Actual observed values collected from captive-reared free-ranging hellbenders in the North Fork of the White River, Arkansas, USA, 2008-2009. Dashed lines are 95\% confidence intervals. Note that scales vary for each regression 
Table 1. Timeline of events involving captive-reared Ozark hellbenders Cryptobranchus alleganiensis bishopi translocated to the North Fork of the White River, Missouri, USA, from May 2008 to August 2009. U: upper site; L: lower site. Events are abbreviated as follows: I: transmitter implant; R: release; EX: excluded (due to mortality before $30 \mathrm{~d}$ or unknown fate); CP: individual was recaptured; XM: surgery for transmitter replacement; BL: blood drawn at recapture. Light shading indicates that animals were living in the wild and dark shading indicates that animals were maintained in captivity

\begin{tabular}{|c|c|c|c|c|c|c|c|c|c|c|c|c|c|c|c|c|c|}
\hline \multirow{2}{*}{$\begin{array}{l}\text { Indivi- } \\
\text { dual no. }\end{array}$} & \multirow[t]{2}{*}{ Site } & \multirow{2}{*}{\multicolumn{2}{|c|}{ May Jun }} & \multirow{2}{*}{ Jul } & \multicolumn{2}{|c|}{2008} & \multirow[b]{2}{*}{ Oct } & \multirow[b]{2}{*}{ Nov } & \multirow[b]{2}{*}{ Dec } & \multirow[b]{2}{*}{ Jan } & \multirow[b]{2}{*}{ Feb } & \multirow[b]{2}{*}{ Mar } & \multirow[b]{2}{*}{ Apr } & \multirow{2}{*}{$\begin{array}{c}-2009 \\
\text { May }\end{array}$} & \multirow[b]{2}{*}{ Jun } & \multirow[b]{2}{*}{ Jul } & \multirow[b]{2}{*}{ Aug } \\
\hline & & & & & Aug & Sep & & & & & & & & & & & \\
\hline 10 & L & $\mathrm{I}, \mathrm{R}$ & & & & & $\mathrm{CP}$ & & & & & & & & & & $\mathrm{CP}, \mathrm{BL}$ \\
\hline 40 & $\mathrm{~L}$ & $\mathrm{I}, \mathrm{R}$ & & & & & $\mathrm{CP}$ & & & & & & & & & & $\mathrm{CP}, \mathrm{BL}$ \\
\hline 90 & $\mathrm{~L}$ & $\mathrm{I}, \mathrm{R}$ & & & & & $\mathrm{CP}$ & & & & & & & $\mathrm{CP}, \mathrm{BL}, \mathrm{M}$ & & & \\
\hline 100 & $\mathrm{~L}$ & $\mathrm{I}, \mathrm{R}$ & & & & & $\mathrm{CP}$ & & & & & & & CP,BL & & & $\mathrm{CP}, \mathrm{BL}$ \\
\hline 120 & $\mathrm{~L}$ & $\mathrm{I}, \mathrm{R}$ & & & & & $\mathrm{CP}$ & & & & & & & $\mathrm{CP}, \mathrm{BL}$ & EX & & $\mathrm{CP}, \mathrm{BL}$ \\
\hline 200 & $\mathrm{~L}$ & $\mathrm{I}, \mathrm{R}$ & & & & & $\mathrm{CP}$ & & & & & $\mathrm{CP}, \mathrm{XM}, \mathrm{S}$ & & $\mathrm{R}$ & & & $\mathrm{CP}, \mathrm{BL}$ \\
\hline 210 & $\mathrm{U}$ & $\mathrm{I}, \mathrm{R}$ & & & & & & & & & & & & & & & $\mathrm{CP}, \mathrm{BL}$ \\
\hline 240 & $\mathrm{U}$ & $\mathrm{I}, \mathrm{R}$ & & & & & $\mathrm{CP}$ & & & & & & & & & $\mathrm{CP}, \mathrm{BL}$ & \\
\hline 260 & $\mathrm{U}$ & $\mathrm{I}, \mathrm{R}$ & & & & & & & & & & & & & & & $\mathrm{CP}, \mathrm{BL}$ \\
\hline 250 & U & $\mathrm{I}, \mathrm{R}$ & & & $\mathrm{CP}, \mathrm{XN}$ & & & & & & & & & $\mathrm{R}$ & EX & EX & $\mathrm{CP}, \mathrm{BL}$ \\
\hline 160 & $\mathrm{U}$ & $\mathrm{I}, \mathrm{R}$ & & & & & $\mathrm{CP}$ & & & & & & & & & $\mathrm{CP}, \mathrm{BL}$ & $\mathrm{CP}, \mathrm{BL}$ \\
\hline 1030 & $\mathrm{U}$ & & & I & $\mathrm{R}, \mathrm{U}$ & & $\mathrm{CP}$ & & & & & & & $\mathrm{CP}, \mathrm{BL}$ & & & $\mathrm{CP}, \mathrm{BL}$ \\
\hline 1170 & $\mathrm{~L}$ & & & I & $\mathrm{R}, \mathrm{L}$ & & $\mathrm{CP}$ & & & & & & & $\mathrm{CP}, \mathrm{BL}$ & & & $\mathrm{CP}, \mathrm{BL}$ \\
\hline 1510 & $\mathrm{~L}$ & & & I & $\mathrm{R}, \mathrm{L}$ & & $\mathrm{CP}$ & & & & & & & & & & $\mathrm{CP}, \mathrm{BL}$ \\
\hline 230 & $\mathrm{U}$ & I & & & $\mathrm{R}, \mathrm{U}$ & & $\mathrm{M}$ & & & & & & & & & & \\
\hline 20 & $\mathrm{U}$ & I & & & $\mathrm{R}, \mathrm{U}$ & & M & & & & & & & & & & \\
\hline 1050 & $\mathrm{~L}$ & & & & & I & $\mathrm{R}, \mathrm{CP}$ & & & & & $\mathrm{CP}, \mathrm{XM}$ & & $\mathrm{R}$ & & & $\mathrm{CP}, \mathrm{BL}$ \\
\hline 1690 & $\mathrm{U}$ & & & & & I & $\mathrm{R}$ & & & & & & & & EX & & $\mathrm{CP}, \mathrm{BL}$ \\
\hline 1650 & $\mathrm{U}$ & & & & & I & $\mathrm{R}$ & & & & & CP,XM & $\mathrm{M}$ & & & & \\
\hline 1630 & $\mathrm{U}$ & & & & & I & $\mathrm{R}$ & $\mathrm{CP}$ & & & & & & $\mathrm{CP}, \mathrm{XM}, \mathrm{M}$ & & & \\
\hline 1710 & $\mathrm{~L}$ & & & & & I & $\mathrm{R}$ & & & & & $\mathrm{CP}, \mathrm{XM}$ & & $\mathrm{R}$ & & M & \\
\hline
\end{tabular}

mean water temperature of each individual's location, squared $\left(\mathrm{Temp}^{2}\right.$; expected quadratic relationships with body condition and survival; Hutchison \& Hill 1976) as predictor variables, and site and absence (if the animal had been temporarily removed from the wild for reimplantation of a radio transmitter [n $=6]$ ) as random variables in both sets of candidate GLMMs fit by maximum likelihood. We scaled and centered all continuous variables. Reimplantation of radio transmitters had the potential to negatively affect body condition or survival. However, analysis of this effect was not an objective of our study so we controlled for this factor as a random variable. In models including the quadratic temperature variable, we included both temperature and temperature squared terms of the centered temperature values (Franklin et al. 2000). For all predictor variables we used only locations recorded between each individual's first and last mass recording. We used Akaike's information criterion adjusted for small sample size (AICc) to rank both sets of models (Burnham \& Anderson 2002). We used model averaging to determine parameter coefficients, standard error, and pvalues for each predictor variable in both candidate model sets (Burnham \& Anderson 2002). Data are presented as means \pm SD unless otherwise indicated.

\section{RESULTS}

At release, the mean percentage difference between observed and expected body mass was $-7.69 \pm$ $12.95 \%$ (range $=-24.32$ to $25.82 \%$ ). Upon final capture, the mean percentage difference between observed and expected mass was $-1.66 \pm 16.01 \%$ (range $=-30.49$ to $48.47 \%$ ). Days observed alive averaged $343 \pm 131.0$ (range $=49$ to $457 \mathrm{~d}$ ) and days observed alive between release and final mass measurement averaged $325 \pm 132.1$ (range $=49$ to $457 \mathrm{~d}$ ). The mean number of locations per hellbender used to calculate proportional use of coarse substrate, distance to cover, and temperature was $118 \pm 59.9$ (range $=25$ to 193) and the mean number of locations used for distance moved was $138 \pm 67.7$ (range $=35$ to 225). Among mean values calculated for each of the 21 hellbenders, the proportion of locations in coarse substrate averaged 70.8 to $36.3 \%$ (range $=0$ to $100 \%$ ), distance to cover rock averaged $0.53 \pm 0.76 \mathrm{~m}$ (range $=0.01$ to $3.05 \mathrm{~m}$ ), distance between observations averaged $3.84 \pm 5.92 \mathrm{~m}$ (range $=0.04$ to $27.20 \mathrm{~m}$ ) and average water temperature was $18.37 \pm 1.63^{\circ} \mathrm{C}$ (range $=14.51$ to $21.49^{\circ} \mathrm{C}$ ) .

The model including only distance between movement observations received $97 \%$ of model weight for 
predicting change in body condition (Table 2). When we transformed the estimated parameter coefficient for distance between observations as a predictor of body condition back to grams using our sample's

Table 2. Model fitting results for predicting change in body condition and fate of Ozark hellbenders Cryptobranchus alleganiensis bishopi at 2 sites in the North Fork of the White River, Missouri, May 2008-August 2009. Site and whether animal was removed for reimplantation of radio transmitter were included as random effects. Change in difference between observed mass ( $\log _{10}$; g) and that expected based on observations by Peterson et al. (1983) divided by number of days observed free-ranging and alive was used as a metric of change in body condition. Fate was used as a metric of survival. Models are shown in rank order from most to least supported by Akaike's information criterion corrected for small sample size (AICc). Coarse is the proportional number of observations of each animal on cobble or boulder stream substrate. Cover is the mean distance $(\mathrm{m})$ of each animal's locations to the nearest rock with at least 1 dimension $\geq 15 \mathrm{~cm}$. Movement is the mean distance between radio locations for each individual animal ( $m$; limited to 1 location per day). Temp and Temp ${ }^{2}$ were always modeled together as a quadratic variable of mean temperature of water at locations of each animal $\left({ }^{\circ} \mathrm{C}\right) . K$ is the number of parameters used to estimate dependent variable including intercept and error term. $w$ is the model weight, representing strength of a model compared with other models in the set (Burnham \& Anderson 2002)

\begin{tabular}{|c|c|c|c|c|c|}
\hline $\begin{array}{l}\text { Biological outcome } \\
\text { Predictors }\end{array}$ & $K$ & $\mathrm{AIC}_{\mathrm{C}}$ & $\Delta \mathrm{AIC}_{\mathrm{C}}$ & $w$ & Pseudo- $\mathrm{R}^{2}$ \\
\hline \multicolumn{6}{|l|}{$\Delta$ Body condition } \\
\hline Movement & 5 & -230.52 & 0.00 & 0.97 & -0.045 \\
\hline Null & 4 & -223.55 & 6.97 & 0.03 & - \\
\hline Coarse+Movement & 6 & -211.45 & 19.06 & 0.00 & 0.020 \\
\hline Cover+Movement & 6 & -211.25 & 19.27 & 0.00 & 0.021 \\
\hline Coarse & 5 & -206.50 & 24.02 & 0.00 & 0.058 \\
\hline Cover & 5 & -206.28 & 24.23 & 0.00 & 0.059 \\
\hline Coarse+Cover+Movement & 6 & -192.00 & 38.52 & 0.00 & 0.083 \\
\hline Coarse+Cover & 5 & -189.30 & 41.22 & 0.00 & 0.114 \\
\hline Movement+Temp ${ }^{2}$ & 7 & -188.53 & 41.99 & 0.00 & 0.098 \\
\hline $\mathrm{Temp}^{2}$ & 6 & -183.89 & 46.63 & 0.00 & 0.137 \\
\hline Cover+Movement+Temp ${ }^{2}$ & 7 & -174.52 & 55.99 & 0.00 & 0.135 \\
\hline Coarse+Movement+Temp ${ }^{2}$ & 7 & -170.40 & 60.12 & 0.00 & 0.152 \\
\hline Coarse+Temp ${ }^{2}$ & 6 & -165.63 & 64.88 & 0.00 & 0.196 \\
\hline Cover+Temp ${ }^{2}$ & 6 & -164.28 & 66.24 & 0.00 & 0.201 \\
\hline Global & 7 & -153.04 & 77.48 & 0.00 & 0.199 \\
\hline Coarse+Cover+Temp ${ }^{2}$ & 8 & -146.30 & 84.22 & 0.00 & 0.255 \\
\hline \multicolumn{6}{|l|}{ Fate } \\
\hline Null & 4 & 32.54 & 0.00 & 0.19 & - \\
\hline Movement+Temp ${ }^{2}$ & 7 & 32.59 & 0.05 & 0.18 & 0.419 \\
\hline Coarse & 5 & 32.83 & 0.29 & 0.16 & 0.111 \\
\hline $\mathrm{Temp}^{2}$ & 6 & 33.50 & 0.97 & 0.12 & 0.224 \\
\hline Movement & 5 & 34.10 & 1.56 & 0.09 & 0.061 \\
\hline Coarse+Movement & 6 & 34.65 & 2.11 & 0.06 & 0.178 \\
\hline Cover & 5 & 35.06 & 2.53 & 0.05 & 0.022 \\
\hline Coarse+Cover & 6 & 35.66 & 3.12 & 0.04 & 0.138 \\
\hline Coarse+Movement+Temp ${ }^{2}$ & 8 & 36.84 & 4.30 & 0.02 & 0.434 \\
\hline Cover+Movement & 6 & 36.91 & 4.37 & 0.02 & 0.088 \\
\hline Coarse+Temp ${ }^{2}$ & 7 & 37.08 & 4.54 & 0.02 & 0.241 \\
\hline Cover+Movement+Temp ${ }^{2}$ & 8 & 37.18 & 4.64 & 0.02 & 0.420 \\
\hline Cover+Temp ${ }^{2}$ & 7 & 37.46 & 4.92 & 0.02 & 0.226 \\
\hline Coarse+Cover+Movement & 7 & 38.15 & 5.61 & 0.01 & 0.198 \\
\hline Coarse+Cover+Temp ${ }^{2}$ & 8 & 40.75 & 8.21 & 0.01 & 0.278 \\
\hline Global & 9 & 41.24 & 8.70 & 0.00 & 0.473 \\
\hline
\end{tabular}

ments). All other modeled predictors of change in body condition had little effect (Table 3). There was much less certainty in models predicting fate, with the null model most supported and competing with models containing distance between locations, temperature, and use of coarse substrate (Table 2). There was little certainty in the effects of predictor variables on fate, but use of coarse substrate had the lowest p-value of 0.187 (Table 3 ).

Six of 21 individuals died: 1 related to chytrid fungus infection, 2 in captivity shortly after reimplantation, 1 radiotracked to a snapping turtle (presumably consumed), and 2 of unknown causes. Mortalities occurred in individuals with changes in body condition ranging from $-25 \%$ to $39 \%$ $($ mean $=2 \%)$. A GLMM of fate predicted by change in body condition with site and absence as random effects was not supported ( $\mathrm{p}=0.19$, pseudo- $R^{2}=0.087$ ).

\section{DISCUSSION}

The energetic metric of distance moved between observations predicted body condition better than traditional metrics of use of substrate features. Variation in the use of coarse substrate and distance to cover suggest the potential for variation in biological outcomes (Aldridge \& Boyce 2008). However, our model selection results indicate that variation in biological outcomes was not explained by variation in use of substrate features over a relatively short time period (i.e. $1 \mathrm{yr})$.

Our results indicate that metrics of energy expenditure or use - such as distance moved - may improve investigations of causes of variation in body condition. Using the most direct measures of resource use (i.e. those affect- 
Table 3. Model-averaged estimates and standard errors (SE) of predictor variables of change in body condition and fate of Ozark hellbenders Cryptobranchus alleganiensis bishopi in the North Fork of the White River, Missouri, from May 2008 to August 2009. For details of predictors see Table 2. RI: Relative importance

\begin{tabular}{|lccccc|}
\hline $\begin{array}{l}\text { Biological outcome } \\
\text { Predictors }\end{array}$ & Estimate & SE & $p$ & RI \\
\hline $\begin{array}{l}\Delta \text { Body condition } \\
\text { Movement }\end{array}$ & $-1.07 \times 10^{-4}$ & $1.24 \times 10^{-5}<0.001$ & 0.97 \\
Coarse & $-1.20 \times 10^{-4}$ & $2.05 \times 10^{-4}$ & 0.557 & 0.00 \\
Cover & $1.23 \times 10^{-4}$ & $1.04 \times 10^{-4}$ & 0.236 & 0.00 \\
Temp & $8.30 \times 10^{-5}$ & $9.88 \times 10^{-5}$ & 0.401 & 0.00 \\
Temp & $3.61 \times 10^{-5}$ & $4.07 \times 10^{-5}$ & 0.374 & 0.00 \\
Fate & & & & & \\
Movement & 0.37 & 0.54 & 0.496 & 0.41 \\
Temp & -1.07 & 0.98 & 0.277 & 0.38 \\
Temp & & 0.16 & 0.30 & 0.592 & 0.38 \\
Coarse & -2.30 & 1.74 & 0.187 & 0.32 \\
Cover & -0.10 & 0.99 & 0.923 & 0.16 \\
\hline
\end{tabular}

ing energetics) may be a better approach than using landcover because energy has a more direct effect on an animal's ability to survive and reproduce than many habitat selection metrics (Homyack 2010, Ayers et al. 2013). For example, energetic expenditure has been demonstrated to have a significant effect on body condition of many species through lipid storage (Speakman 2001). Hellbenders will encounter a variety of distributions of important resources within their habitat that may affect their energetics. Therefore, distribution of resources has the potential to affect the energy economics that influence animal survival and reproduction (Bearhop et al. 2004, Walker \& Lindberg 2005). Our results suggest that increased energy expenditure will decrease hellbender body condition; however, our 2 biological outcomes were not predicted similarly. Fate was not clearly supported by any resource-use metric, but distance moved and temperature competed for support, indicating that our observations may have included movement and temperature use habits that could eventually limit biological outcomes (Hutchison \& Hill 1976). Further, the lack of correlation between body condition and fate indicates that condition may not always be an accurate index of an animal's ability to survive and reproduce, as is often assumed, especially in short studies of long-lived species (Hayes \& Shonkwiler 2001). Hellbenders can live for more than 20 yr (Nickerson \& Mays 1973, Taber et al. 1975, Peterson et al. 1983), and while most individuals in our study were observed for more than a year, this amount of time may not suffice for learning the full effects of decreased body condition on the ultimate fate of the animal. Alternatively, perhaps body condition declines within the ranges we observed do not limit hellbender survival. Also, most causes of death of our study animals did not appear to relate to negative changes in body condition. In fact, when comparing body conditions we observed with body conditions we expected based on data from Peterson et al. (1983), our observations were within the confidence intervals of expected values at both release and final observation, with only one exception.

Examples of additional potential factors causing variation in biological outcomes may include consumption rates of food items or constraints of territoriality (Gaillard et al. 2010). Bodinof et al. (2012a) found similar abundance of crayfish at both study sites; however, consumption rates of crayfish by hellbenders may vary among microhabitats of pools, riffles, and runs due to differences in crayfish vulnerability. Changes to crayfish distribution through habitat change could have important effects on hellbender success. Although Bodinof et al. (2012a) investigated hellbender selection of pools, riffles, and runs and found no differences between these areas, consumption rates of crayfish in each microhabitat should be investigated for effects on energetics. Additionally, as with any territorial species, consumption rates of prey may vary between individuals if a social hierarchy creates a despotic hellbender distribution (Fretwell 1972).

Individual resource use is most likely not the only influence on hellbender survival and recruitment. Examples of extrinsic factors suggested to potentially affect Ozark hellbender populations include impoundments affecting flow and temperature of water, sedimentation, water contamination, predation, disease, and disturbance (Briggler et al. 2007, Solís et al. 2007, Bodinof et al. 2011, Gould 2011). Perhaps measures of energetics and extrinsic factors can be simultaneously related to an accurate index of fitness such as lifetime reproductive success to gain a clearer understanding of causes of variation in individual hellbender biological outcome.

Management of habitat affecting hellbender biological outcomes through energetic metrics may benefit population recoveries. Though we were not able to detect a correlation between body condition and fate, chronically low or continuously declining body condition is likely to reduce survival and lifetime reproductive success of hellbenders (Speakman 2001). Therefore, management of habitat to decrease lengthy or frequent movements may be beneficial for hellbender conservation. While reintroduction efforts 
can be used to increase numbers of adults, identification of characteristics of successful recruitment in the wild are necessary for long-term population persistence (Wheeler et al. 2003). Modeling of successful hellbender recruitment may help us understand factors with the greatest effects on population persistence better than investigations of adult resource use when resource management cannot be used to sufficiently improve adult body condition or survival. Measures of body condition and survival are common indices for fitness, but should be tested for their usefulness in understanding animal ecology (Homyack 2010), as we have demonstrated.

Recovery of the Ozark hellbender may require a greater understanding of the species' ecology before making appropriate recommendations for resource management. Amphibians around the world have served as indicator species of ecosystem degradation for decades (Kerby et al. 2010). Ozark hellbenders face many potential threats throughout their range, but we have demonstrated that short-term use of known selected resources does not limit hellbender biological outcomes. It is therefore important to investigate long-term effects of resource use and other metrics of individual hellbender energetics, as well as extrinsic factors considered to have the greatest effects on individual fitness, to adapt management toward preventing further declines of this species.

Acknowledgements. We thank B. Leopold for reviewing this manuscript. We thank the Mississippi State University Forest and Wildlife Research Center, The University of Missouri, and Missouri Department of Conservation for funding this research. Also, we thank the Missouri Department of Conservation for permitting our data collection. Permits for working with these animals were provided by the Missouri Department of Conservation (nos. 13830 and 14180).

\section{LITERATURE CITED}

Aldridge CL, Boyce MS (2008) Accounting for fitness: combining survival and selection when assessing wildlifehabitat relationships. Isr J Ecol Evol 54:389-419

> Ayers CR, Belant JL, Millspaugh JJ (2013) Directness of resource use metrics affects predictions of bear body fat gain. Polar Biol 36:169-176

Bearhop S, Hilton GM, Votier SC, Waldron S (2004) Stable isotope ratios indicate that body condition in migrating passerines is influenced by winter habitat. Proc Biol Sci 271:S215-S218

Blouin-Demers G, Weatherhead PJ (2001) Habitat use by black rat snakes (Elaphe obsoleta obsoleta) in fragmented forests. Ecology 82:2882-2896

Bodinof CM, Briggler JT, Duncan MC, Beringer J, Millspaugh JJ (2011) Historic occurrence of the amphibian chytrid fungus Batrachochytrium dendrobatidis in hell- bender Cryptobranchus alleganiensis populations from Missouri. Dis Aquat Org 96:1-7

Bodinof CM, Briggler JT, Junge RE, Beringer J and others (2012a) Habitat attributes associated with short-term settlement of Ozark hellbender (Cryptobranchus alleganiensis bishopi) salamanders following translocation to the wild. Freshw Biol 57:178-192

- Bodinof CM, Briggler JT, Junge RE, Mong $\mathrm{T}$ and others (2012b) Survival and body condition of captive-reared juvenile Ozark hellbenders (Cryptobranchus alleganiensis bishopi) following translocation to the wild. Copeia 2012:150-159

Briggler J, Utrup J, Davidson C, Humphries J and others (eds) (2007) Hellbender population and viability assessment: Final report. IUCN/SSC Conservation Breeding Specialist Group, Apple Valley, MN

Burnham KP, Anderson DR (2002) Model selection and multimodel inference: a practical information-theoretic approach. Springer, New York, NY

Darwin C (1859) On the origin of species by means of natural selection, or the preservation of favoured races in the struggle for life. John Murray, London

$>$ Franklin AB, Anderson DR, Gutierrez RJ, Burnham KP (2000) Climate, habitat quality, and fitness in northern spotted owl populations in northwestern California. Ecol Monogr 70:539-590

Fretwell SD (1972) Populations in a seasonal environment. Princeton University Press, Princeton, NJ

Gaillard JM, Hebblewhite M, Loison A, Fuller M, Powell R, Basille M, Van Moorter B (2010) Habitat-performance relationships: finding the right metric at a given spatial scale. Philos Trans R Soc Lond B 365:2255-2265

Gould RW (2011) Endangered and threatened wildlife and plants; endangered status for the Ozark hellbender salamander. Fed Regist 76:61956-61978

> Halstead BJ, Wylie GD, Amarello M, Smith JJ, Thompson ME, Routman EJ, Casazza ML (2011) Demography of San Francisco gartersnake in coastal San Mateo County, California. J Fish Wildl Manag 2:41-48

Hayes J, Shonkwiler J (2001) Mophometric indicators of body condition: worthwhile or wishful thinking? In: Speakman JR (ed) Body composition analysis of animals. Cambridge University Press, New York, NY, p 8-38

Homyack JA (2010) Evaluating habitat quality of vertebrates using conservation physiology tools. Wildl Res 37 : 332-342

Hutchison VH, Hill LG (1976) Thermal selection in the hellbender, Cryptobranchus alleganiensis, and the mudpuppy, Necturus maculosus. Herpetologica 32:327-331

> Kerby JL, Richards-Hrdlicka KL, Storfer A, Skelly DK (2010) An examination of amphibian sensitivity to environmental contaminants: Are amphibians poor canaries? Ecol Lett 13:60-67

Mautz WW, Fair J (1980) Energy expenditure and heart rate for activities of white-tailed deer. J Wildl Manag 44: 333-342

Millspaugh JJ, Washburn BE (2004) Use of fecal glucocorticoid metabolite measures in conservation biology research: considerations for application and interpretation. Gen Comp Endocrinol 138:189-199

Nickerson MA, Mays CE (1973) The hellbenders: North American 'giant salamanders'. Milwaukee Public Museum Press, Milwaukee, WI

Nie H, Song Y, Zeng Z, Zhang Q (2011) Life history pattern and fitness of an endangered Hainan Eld's deer popula- 
tion. Integr Zool 6:63-70

Peterson CL, Wilkinson RF, Topping MS, Metter DE (1983) Age and growth of the Ozark hellbender (Cryptobranchus alleganiensis bishopi). Copeia 1983:225-231

Peterson CL, Metter DE, Miller BT, Wilkinson RF, Topping MS (1988) Demography of the hellbender Cryptobranchus alleganiensis in the Ozarks. Am Midl Nat 119: 291-303

Solís ME, Liu CC, Nam P, Niyogi DK, Bandeff JM, Huang YW (2007) Occurrence of organic chemicals in two rivers inhabited by Ozark hellbenders (Cryptobranchus alleganiensis bishopi). Arch Environ Contam Toxicol 53: 426-434

Speakman JR (ed) (2001) Introduction. In: Body composition analysis of animals. Cambridge University Press, New York, NY, p 1-7

Stevenson RD, Woods WA Jr (2006) Condition indices for

Editorial responsibility: Brendan Godley,

University of Exeter, Cornwall Campus, UK conservation: new uses for evolving tools. Integr Comp Biol 46:1169-1190

Taber CA, Wilkinson RF Jr, Topping MS (1975) Age and growth of hellbenders in the Niangua River, Missouri. Copeia 1975:633-639

Thomas CD (1990) What do real population dynamics tell us about minimum viable population sizes? Conserv Biol 4: 324-327

Thomas DLE, Taylor J (2006) Study designs and tests for comparing resource use and availability II. J Wildl Manag 70:324-336

Walker J, Lindberg MS (2005) Survival of scaup duckling in the boreal forest of Alaska. J Wildl Manag 69:592-600

Wheeler BA, Prosen E, Mathis A, Wilkinson RF (2003) Population declines of long-lived salamander: a 20+ year study of hellbenders, Cryptobranchus alleganiensis. Biol Conserv 109:151-156

Submitted: August 30, 2012; Accepted: June 3, 2013

Proofs received from author(s): August 16, 2013 